\title{
Effect of Temperature and Water Potential on Survival and Mycelial Growth of Phaeomoniella chlamydospora and Phaeoacremonium spp.
}

\author{
E. C. Whiting, A. Khan, and W. D. Gubler, Department of Plant Pathology, University of California, Davis 95616
}

\begin{abstract}
Whiting, E. C., Khan, A., and Gubler, W. D. 2001. Effect of temperature and water potential on survival and mycelial growth of Phaeomoniella chlamydospora and Phaeoacremonium spp. Plant Dis. 85:195-201.

Phaeomoniella chlamydospora, a species of Phaeomoniella, and two species of Phaeoacremonium, $P$. inflatipes and $P$. aleophilum, have been associated with young grapevine decline in major production regions of California. Phaeomoniella chlamydospora has been isolated from healthy vines and inoculated but non-symptomatic vines and rooted cuttings. Effects of temperature and water potential on fungal response in culture were investigated to find effective control strategies for nurseries. Mycelial growth rates at temperatures 5 to $37^{\circ} \mathrm{C}$ showed a quadratic response with optimum growth rates for Phaeomoniella chlamydospora and P. aleophilum at $25^{\circ} \mathrm{C}$ and at $30^{\circ} \mathrm{C}$ for $P$. inflatipes. Response to water potential varied by isolates within a species, but isolates of Phaeomoniella chlamydospora were not sensitive to decreasing water potential. A conidial suspension and plugs of agar with mycelia were placed in glass vials and incubated in hot water for 15 to $120 \mathrm{~min}$. Conidia were sensitive to hot-water treatment after 15 and $30 \mathrm{~min}$. Nevertheless, mycelia of $P$. inflatipes from agar plugs grew on potato dextrose agar at $22^{\circ} \mathrm{C}$ after $120 \mathrm{~min}$ incubation at $51^{\circ} \mathrm{C}$. Because the fungi were not killed by incubation in glass vials at $51^{\circ} \mathrm{C}$, methods other than hot-water treatment may be more effective in eliminating Phaeomoniella chlamydospora and Phaeoacremonium spp. from dormant vine cuttings.
\end{abstract}

Additional keywords: Vitis vinifera

A decline of young grapevines was reported in major production regions of California beginning in the early 1990s. Decline and dieback of young vines had been observed as early as 1940 in South Africa (10). Grapevine decline is now a growing problem in Australia (20) and was first observed in Sicily in 1998 (24). In California many growers are replanting vines in areas of vineyards that show poor vine establishment and also replanting areas where vines are growing slowly. Viticulturists reporting the problem were in areas where replanting had been done with phylloxera-resistant rootstocks (22). Although a few replants in a vineyard may not be economically significant, some growers are replanting large areas. In these cases, replanting costs will be high and growers are understandably concerned about increasing problems with poor early vine growth and vigor.

Grapevines affected by Phaeomoniella chlamydospora Crous et W. Gams, gen. nov. (formerly Phaeoacremonium chlamydosporum) (7) and other Phaeoacremonium species show symptoms of poor early

Corresponding author: E. C. Whiting

E-mail: ecwhitin@valdosta.edu

Accepted for publication 2 November 2000.

Publication no. D-2000-1212-02R

(C) 2001 The American Phytopathological Society growth and reduced vine vigor. Vines later become stunted. Declining vines show decreased trunk caliper size, have shortened internodes, reduced amount of foliage, and smaller leaf size (23). Three to 5 years after planting, foliar symptoms develop that can include interveinal chlorosis and marginal necrosis and wilting, which may ultimately result in premature defoliation. When viewed in cross-section, vessels in the xylem of the root crown and lower rootstock of declining vines appear as dark-brown to black spots. In longitudinal view, vessel elements appear as dark streaks. The streaking of occluded vessels occurs near the pith, which may also be abnormally dark. Root systems of declining vines also have less total root biomass, reduced numbers of white feeder roots, and dry, brown lesions on feeder roots. Isolations made from the discolored vessels, from the area around the darkened pith, and from roots consistently yielded Phaeomoniella chlamydospora and P. inflatipes. Another species of Phaeoacremonium, $P$. aleophilum, has also been isolated from symptomatic root tissue of vines in California, although not as often as the other two fungi (23).

Phaeomoniella chlamydospora and several species of Phaeoacremonium are also associated with a destructive disease of woody tissue of older vines known as "black measles" or esca $(8,14,18,26)$.

Nurseries in Australia routinely use a hot water treatment for propagation mate- rial as a prophylactic measure (27). Dormant rootstocks and cuttings are subjected to $50^{\circ} \mathrm{C}$ in a water bath for $30 \mathrm{~min}$ as the standard treatment. Treatment for this length of time reportedly inhibits most fungal and bacterial pathogens but does not harm dormant buds. Phylloxera (17), nematodes (16), Pierce's disease (11), Phytophthora cinnamomi (2), crown gall (4), and phytoplasmas, particularly Australian Grapevine Yellows, are inhibited by this treatment (5). Nurseries in California are beginning to use this method for their nursery stock. However, there has been no reported information of the effects of high temperatures on Phaeomoniella or Phaeoacremonium spp. in vitro or in vivo.

In California, Phaeomoniella chlamydospora and Phaeoacremonium spp. have been isolated from healthy vines and have been recovered from inoculated but nonsymptomatic vines (22). In Italy, Phaeomoniella chlamydospora has been isolated from healthy rooted cuttings (1). Phaeomoniella and Phaeoacremonium spp. may exist as endophytes or as latent infections in vine tissue and elicit plant response only when vines are stressed. Vines may experience stress from many different, multiple sources including low temperature, water deficit, and stress from early fruiting.

Infection by Phaeomoniella chlamydospora or Phaeoacremonium spp. causes darkening of xylem vessels with production of tyloses and dark gummy masses resulting in occlusion of xylem vessels (23). The fungi can be isolated from woody tissue near occluded xylem vessels. If pathogens exist in the apoplast of the vascular system, they must depend on the host for water and nutrients. In this case, water potential of the host would have a direct effect on the fungi $(3,6)$. Information on how water potential affects Phaeomoniella chlamydospora and Phaeoacremonium spp. would be of interest, but no information about its effects has been reported.

The objective of this research was to provide information on effects of temperature and water potential on isolates of Phaeomoniella chlamydospora and Phaeoacremonium from California. This basic information on fungal response in culture could be valuable in determining effective control strategies for nurseries.

\section{MATERIALS AND METHODS}

Fungal isolates. Nine isolates from various places in California (four isolates 
of Phaeomoniella chlamydospora, two of and one isolate of $P$. aleophilum from South Africa were selected for the studies (Table 1). Isolates used in these studies came from grapevine roots that had typical dark-brown to black vascular streaks.

Effect of temperature on radial colony growth. Three isolates of Phaeomoniella chlamysospora (Pc 44, Pc 65, Pc 84), two isolates of $P$. aleophilum ( $\mathrm{Pa} \mathrm{11,} \mathrm{Pa} 75)$, and two isolates of $P$. inflatipes ( $\mathrm{Pi} 97, \mathrm{Pi}$ 99) were evaluated to determine effect of temperature on radial colony growth in culture. All isolates were maintained on Difco potato dextrose agar amended with $0.1 \mu \mathrm{g} / \mathrm{ml}$ tetracycline (PDA-Tet) at $22^{\circ} \mathrm{C}$. Plugs of agar, $5 \mathrm{~mm}$ in diameter, were cut from the leading edge of colonies growing on PDA-Tet and placed in the center of Petri plates containing 1\% Difco malt extract and agar (MEA). Plates were then wrapped with Parafilm and placed in plasTreatments consisted of eight temperatures: $5,10,15,20,25,30,35$, and $37^{\circ} \mathrm{C}$. The experiment was designed as a random block with four replications of each isolate by temperature treatment. The experiment was repeated once. After 7 days colony diameter was measured along two axes age of the two diameters was recorded as the radial colony diameter. Radial colony diameter was measured every week for 4 weeks.

Water potential and radial colony growth. Three isolates of Phaeomoniella chlamydospora (Pc 44, Pc 62, Pc 65), two isolates each of $P$. aleophilum $(\mathrm{Pa} 11, \mathrm{~Pa}$ 75) and $P$. inflatipes ( $\mathrm{Pi} 61, \mathrm{Pi} 97$ ) were used for this study. Isolates were mainthe experiments. Influence of water potential on radial colony growth was determined at $22^{\circ} \mathrm{C}$ on PDA amended with potassium chloride $(\mathrm{KCl})$ or sucrose at appropriate concentrations prior to sterilization to produce osmotic potentials of $-0.3,-0.8,-1.3,-2.3,-4.3$, and $-8.3 \mathrm{MPa}$. Osmotic potential was calculated by adding the osmotic potential of unamended PDA, -0.3 MPa (25), and the theoretical osmotic potential produced by the addition of solutes according to tables of Robinson $P$. aleophilum, and three of $P$. inflatipes) tic boxes before being placed in incubators. perpendicular to one another and the avertained on PDA-Tet at 21 to $22^{\circ} \mathrm{C}$ prior to

and Stokes (21) and Harris (13). Approximately $40 \mathrm{ml}$ of unamended PDA or amended agar was poured into $90 \times 15 \mathrm{~mm}$ Petri plates. Prior to inoculation, plates were placed at $22^{\circ} \mathrm{C}$ for 24 hours to equilibrate. Agar plugs $5 \mathrm{~mm}$ in diameter were cut with a no. 2 cork borer from the advancing margin of 4-week-old cultures. Plugs with mycelia were placed in the center of Petri plates and sealed with parafilm. There were four replicates of each isolate by water potential by osmoticum combination. Sealed plates were then placed in closed plastic boxes to further reduce evaporation and changes in water potential, and incubated at $22^{\circ} \mathrm{C}$ for four weeks.

Colony growth was measured as before every week for 4 weeks. Viability of mycelia from agar plugs from which no growth occurred was tested by plating agar plugs on unamended PDA-Tet and incubating at $22^{\circ} \mathrm{C}$ for 4 additional weeks. The experiment was repeated once.

Effect of hot-water bath treatment on viability of conidia and mycelia. Viability of fungal conidia and mycelium of one isolate of Phaeomoniella chlamydospora ( $\mathrm{Pc} 44)$ and one isolate of $P$. inflatipes ( $\mathrm{Pi}$ 97) were evaluated at $51^{\circ} \mathrm{C}$ using a hot water bath (Neslab GP-300 Series Constant Temperature Bath, Union City, CA). Screw-cap glass vials, $125 \mathrm{~mm}$ long and 16 $\mathrm{mm}$ in diameter, containing conidia were incubated for 15, 30, 45, and $60 \mathrm{~min}$. Vials containing agar plugs were incubated for $15,30,45,60,90$, and $120 \mathrm{~min}$. The position of the vials was randomized before they were placed in the bath. The run was repeated once, each time with six replications.

Conidia. Plates with growing colonies were flooded with $10 \mathrm{ml}$ of sterile deionized water and conidia were released using a sterile inoculation loop. The spore suspension was filtered through four layers of cheesecloth into a $100 \mathrm{ml}$ erlenmeyer flask. The suspension volume was adjusted to 50 $\mathrm{ml}$. The number of conidia in the stock suspension was counted with a hemacytometer and serially diluted to give a $1 \times$ $10^{5}$ conidia per $\mathrm{ml}$ suspension. Five $\mathrm{ml}$ aliquots of the conidial suspension were pipetted into each of 24 vials. Treatments consisted of four incubation periods with

Table 1. Source of Phaeomoniella chlamydospora, Phaeoacremonium aleophilum, and Phaeoacremonium inflatipes isolates obtained from grapevine roots with dark-brown-to-black vascular streaks

\begin{tabular}{lcc}
\hline Species & Isolate & Geographic origin \\
\hline P. aleophilum & $\mathrm{Pa} 51$ & South Africa \\
P. aleophilum & $\mathrm{Pa} 11$ & California, Riverside County \\
P. aleophilum & $\mathrm{Pa} 75$ & California, Coachella Valley \\
P. chlamydosporum & $\mathrm{Pc} 44$ & California, Mendocino County \\
P. chlamydosporum & $\mathrm{Pc} 62$ & California, Sonoma County \\
P. chlamydosporum & $\mathrm{Pc} 65$ & California, Napa Valley \\
P. chlamydosporum & $\mathrm{Pc} 84$ & California, Mendocino County \\
P. inflatipes & $\mathrm{Pi} 61$ & California, Sonoma County \\
P. inflatipes & $\mathrm{Pi} 97$ & California, Central Valley \\
P. inflatipes & $\mathrm{Pi} 99$ & California, Sonoma Valley \\
\hline
\end{tabular}

six replications in each period. To serve as a control $(0 \mathrm{~min}), 0.1 \mathrm{ml}$ aliquots of the conidial suspension were pipetted onto the surface of each of six $1.5 \%$ water agar (WA) plates and the droplets were spread with a sterile bent-glass rod to distribute spores evenly on the plate. Control plates were placed in covered plastic boxes and incubated at $22^{\circ} \mathrm{C}$.

After each incubation time, $0.1 \mathrm{ml}$ of the conida suspension was pipetted onto each of six $1.5 \%$ WA plates and spread with a sterile bent-glass rod. After 24, 48, and 72 $\mathrm{h}$, three drops of lacto-phenol cotton blue were pipetted with a pasteur pipet onto $1.5 \%$ WA plates with conidia and drops were covered with cover slips. Viability of conidia was assessed by counting the number of conidia out of 200 that had germinated at each assessment time. Conidia were considered to have germinated if the germ tube was one-half the length of the spore.

Mycelia. Plugs of agar with mycelia and spores, $4 \mathrm{~mm}$ diameter, were cut from the growing edge of 2- to 4-week-old colonies growing on PDA-Tet. An agar plug was placed into each of 36 vials containing 5 $\mathrm{ml}$ of sterile deionized water. Six plugs were placed in the center of six plates of PDA-Tet to serve as the control treatment (0 min in water bath). Control plates were sealed with parafilm and placed inside plastic boxes and incubated at $22^{\circ} \mathrm{C}$.

Viability of mycelia from agar plugs that had been initially subjected to $51^{\circ} \mathrm{C}$ was assessed by plating treated plugs on PDATet and incubating at $22^{\circ} \mathrm{C}$. Agar plugs were removed from heated vials and blotted briefly, agar side down, on sterile filter paper (Whatman no. 2) before being placed in the center of the petri plates. After 1 week, colony diameter was measured along two axes perpendicular to each other and the average of the two dimensions was recorded as the radial colony diameter.

Sporulation. The number of conidia produced on mycelia from agar plugs that were subjected to $51^{\circ} \mathrm{C}$ was assessed under experimental parameters identical to those that assessed mycelial viability. Agar plugs from vials immersed in the hot-water bath were plated on PDA-Tet and incubated at $22^{\circ} \mathrm{C}$ for 1 week ( $P$. inflatipes) and for 4 weeks (Phaeomoniella chlamydospora). After the incubation period, additional plugs of agar, $4 \mathrm{~mm}$ diameter, were cut from the growing edge of the colonies on PDA-Tet and placed in vials containing 5 $\mathrm{ml}$ of sterile deionized water. Vials with plugs were vortexed $5 \mathrm{sec}$ and the number of spores per $\mathrm{ml}$ was counted using a hemacytometer.

Statistical analysis. To determine if separate runs of the temperature and water potential experiments could be combined, analysis of variance (ANOVA) was performed to test for homogeneity of experimental error variances. All colony diameter data were analyzed using linear 
regression to obtain rates of colony growth over time. Curves were fitted to growthrate data to relate rate of growth over different temperature and water potential treatments. Where appropriate, first-, second-, and third-order polynomials were fit to the data and $F$ and $R^{2}$ values were examined to find curves that best fit the data and described the relationship between rate of growth and treatment levels. Homogeneity of slopes from linear regression of colony growth data over water potential was tested by ANOVA to determine if differences in rates of growth due to osmotica were observed. Statistical analyses were carried out using SAS (SAS System for Windows, V7, SAS Institute, Cary, NC). ANOVA was also performed on water potential within each isolate.

\section{RESULTS}

Temperature. Mycelial growth at different temperatures followed a quadratic response (Fig. 1A to G). Growth was slow between 10 and $15^{\circ} \mathrm{C}$, optimal between 25 and $30^{\circ} \mathrm{C}$, and slow at higher temperatures. None of the isolates grew at $5^{\circ} \mathrm{C}$. Responses of isolates to different temperatures were grouped according to species with isolates of $P$. aleophilum, Phaeomoniella chlamydospora, and $P$. inflatipes having similar cardinal temperatures and rates of growth. Isolates of $P$. aleophilum (Fig. 1A to B) and Phaeomoniella chlamydospora (Fig. 1E to G) both had an optimum temperature of $25^{\circ} \mathrm{C}$, but rates of growth at that temperature differed, while P. inflatipes (Fig. 1C to D) had an optimum temperature of $30^{\circ} \mathrm{C}$.

Cardinal temperatures for growth of isolates of P. aleophilum (Fig. 1A to B) were $10^{\circ} \mathrm{C}$ minimum, $<35^{\circ} \mathrm{C}$ maximum, and $25^{\circ} \mathrm{C}$ optimum. After 16 days, radial colony diameters were 46 to $48 \mathrm{~mm}$ at $25^{\circ} \mathrm{C}$. Maximum rate of growth was $3 \mathrm{~mm}$ per day at the optimum temperature. For isolate $\mathrm{Pa} 75$ (Fig. 1B), however, there was no significant difference in growth rate at 20 or $25^{\circ} \mathrm{C}$. Cardinal temperatures for growth of isolates of Phaeomoniella chlamydospora (Fig. $1 \mathrm{E}$ to $\mathrm{G}$ ) were $15^{\circ} \mathrm{C}$ minimum, $<35^{\circ} \mathrm{C}$ maximum, and $25^{\circ} \mathrm{C}$ optimum. After 16 days, radial colony diameters were 26 to $29 \mathrm{~mm}$ at $25^{\circ} \mathrm{C}$. Maximum rate of growth was $<2 \mathrm{~mm}$ per day at the optimum temperature. Growth rates were from 1.6 and $1.7 \mathrm{~mm}$ per day. Cardinal temperatures for growth of isolates of $P$. inflatipes (Fig. 1C to D) were $10^{\circ} \mathrm{C}$ minimum, $>35 \mathrm{C}$ maximum and $30^{\circ} \mathrm{C}$ optimum. After 16 days radial colony diameters were $47 \mathrm{~mm}$ at $30^{\circ} \mathrm{C}$. Maximum growth rates were 2.9 to $3.3 \mathrm{~mm}$ per day at $30^{\circ} \mathrm{C}$. There was no significant difference in mean rate of growth of isolate $\mathrm{Pi} 97$ (Fig. 1C) at 25 or $30^{\circ} \mathrm{C}$, although radial colony diameter was evidently larger at $30^{\circ} \mathrm{C}$ than at $25^{\circ} \mathrm{C}$.

Water potential. Colony growth within each osmoticum was similar for both runs of the experiment and an $F$ test for homogeneity of experimental error variances showed that runs for each osmoticum could be combined. Slopes of the regression lines for $\mathrm{KCl}$ - and sucrose-amended agar were similar and tests for the homogeneity of regression coefficients (slope) showed that rate of decrease in colony growth due to an incremental change in water potential was not significantly different due to $\mathrm{KCl}$ or to sucrose as the osmoticum. Therefore, changes in rate of colony growth are more likely due to changes in water potential of the medium and are not due to difference or toxicity of the osmoticum.

Response to changes in water potential varied between species and among isolates within species (Fig. 2A to $G$ ). The rate of colony growth declined as water potential decreased for all isolates. Fastest rates of growth occurred down to $-1.3 \mathrm{MPa}$ for most isolates with two isolates maintaining high rates of growth down to $-2.3 \mathrm{MPa}(\mathrm{Pa}$ 75, Pi 97) (Fig. 2B and D). All but one isolate (Pi 61) (Fig. 2C) grew at a water potential of $-8.3 \mathrm{MPa}$. The three isolates of Phaeomoniella chlamydospora followed very similar trends in response to decreasing water potential (Fig. 2E to G). Fastest growth occurred between -0.3 to $-0.8 \mathrm{MPa}$ with rates of 4.8 to $6.5 \mathrm{~mm}$ per week on either $\mathrm{KCl}$ - or sucrose-amended PDA. Growth rates at these water potentials were not significantly different. However, the rate at which the rate of growth declined, the slope of the regression line, was very slow. Slopes were all significantly different from zero $(P<0.05)$ but isolates were unresponsive to lowered water potential.

Response of isolates of $P$. aleophilum (Fig. 2A to B) and P. inflatipes (Fig. 2C to D) differed within each species, but isolates were generally more responsive to changes in water potential than isolates of Phaeomoniella chlamydospora (Fig. 2E to G). Slopes of Pi 97 (Fig. 2D) and $\mathrm{Pa} 75$ (Fig. 2B) were steeper (1.1 to 1.7) indicating that rates of growth fell more sharply as water potential decreased. Rates of growth at $-2.3 \mathrm{MPa}$ were also twice as high (9 to $17 \mathrm{~mm}$ per week) as rates of Phaeomoniella chlamydospora (Fig. 2E to $\mathrm{G})$. There was no significant difference in rates of growth for $\mathrm{Pa} 75$ (Fig. 2B) on either $\mathrm{KCl}$ or sucrose down to $-2.3 \mathrm{MPa}$. Rates of growth on $\mathrm{KCl}$, however, were significantly faster $(P=0.05)$ at lower water potentials, -1.3 to $-2.3 \mathrm{MPa}$, than on unamended agar. There were significant differences in rate of growth for Pi 97 (Fig. 2D) on both $\mathrm{KCl}$ and sucrose. On $\mathrm{KCl}-$ amended agar, growth was significantly faster than on unamended agar. On sucrose amended agar, however, growth rates were faster at lower water potentials, although differences in growth were not significant between -0.8 and $-1.3 \mathrm{MPa}$. Isolates of $\mathrm{Pa}$ 11 (Fig. 2A) and Pi 61 (Fig. 2 C) had rates of growth similar to Phaeomoniella chlamydospora (Fig. 2E to G), 0.8 to $1 \mathrm{~mm}$ per week, but slopes of the regression lines were somewhat steeper (0.6 to 0.9$)$ than those of Phaeomoniella chlamydospora. Nevertheless, slopes were not as steep as the other isolates of $P$. aleophilum and $P$. inflatipes, which indicated less response to decreasing water potential. All isolates that did not grow on media at $-8.3 \mathrm{MPa}$ and were placed subsequently on unamended PDA-Tet, grew after 1 week.

Hot-water treatment. Conidia of Phaeomoniella chlamydospora did not germinate after treatment at $51^{\circ} \mathrm{C}$ for 15 min in the hot water bath (Fig. 3B). Germination of conidia not subject to hotwater treatment was $98 \%$ after $48 \mathrm{~h}$. Germination was also assessed after 72 and 96 $\mathrm{h}$ to allow a lag time for germination to occur. The additional time did not increase germination. No conidia germinated after $15 \mathrm{~min}$ in the water bath. Colony diameter of agar plugs subjected to the heat treatment and subsequently plated on PDA-Tet decreased linearly as length of time in the water bath increased to $60 \mathrm{~min}$ (Fig. 3C). No hyphae grew out from plugs on PDATet after initial treatment of $120 \mathrm{~min}$ in the water bath (Fig. 3D). Rate of colony growth also decreased with increased time in the water bath. Rates of growth declined from $9 \mathrm{~mm}$ per week for controls, to <2 $\mathrm{mm}$ per week for plugs placed in the water bath for $60 \mathrm{~min}$. Sporulation was not affected by hot-water treatment. The number of spores produced from mycelia incubated in tubes for $30 \mathrm{~min}$ and subsequently grown on PDA-Tet at $22^{\circ} \mathrm{C}$ was approximately $10^{6}$ spores $/ \mathrm{ml}$.

Germination of conidia of $P$. inflatipes was $99 \%$ after $24 \mathrm{~h}$ at room temperature (Fig. 3A). No germination of conidia occurred when assessed $24 \mathrm{~h}$ after exposure to $15 \mathrm{~min}$ in the hot water bath. When germination was assessed after $72 \mathrm{~h}, 60 \%$ of conidia germinated after treatment for $15 \mathrm{~min}$ in the water bath. After $30 \mathrm{~min}$ at $51^{\circ} \mathrm{C}$ in the water bath, however, few conidia $(<1 \%)$ germinated even allowing $72 \mathrm{~h}$ before assessment. Colony diameters of plugs with mycelia not placed in the water bath were $37 \mathrm{~mm}$ after four weeks (Fig. 3C). Colony diameter did not decline after plugs were placed in the water bath for all lengths of time tested. Rate of colony growth for controls was $9 \mathrm{~mm}$ per week (Fig. 3D). Rates of growth of plugs treated with hot water increased from 9 to $11 \mathrm{~mm}$ per week even after placement in the water bath for $120 \mathrm{~min}$. Sporulation from plated agar plugs decreased by 10 fold after the initial $15 \mathrm{~min}$ in the water bath, but remained constant even after $120 \mathrm{~min}$. The number of spores produced was $10^{6}$ for controls and $10^{5}$ spores $/ \mathrm{ml}$ after treatment.

\section{DISCUSSION}

Cardinal temperatures for growth of isolates of Phaeomoniella chlamydospora and $P$. inflatipes from California are in agreement with published literature for 
isolates of these species from other regions (8). Rates of growth were not published by Crous et al., but radial colony diameters of isolates of both Phaeomoniella chlamydospora and $P$. inflatipes from California were similar to isolates from other regions: 13 to $14 \mathrm{~mm}$ diameter for isolates of Phaeomoniella chlamydospora from California compared to 10 to $12 \mathrm{~mm}$ for isolates from other regions (8); and, $24 \mathrm{~mm}$ diameter for isolates of $P$. inflatipes from California compared to $26 \mathrm{~mm}$ for isolates from other regions (8). Therefore, rates of mycelia growth at different temperatures can be used to compare effects of different
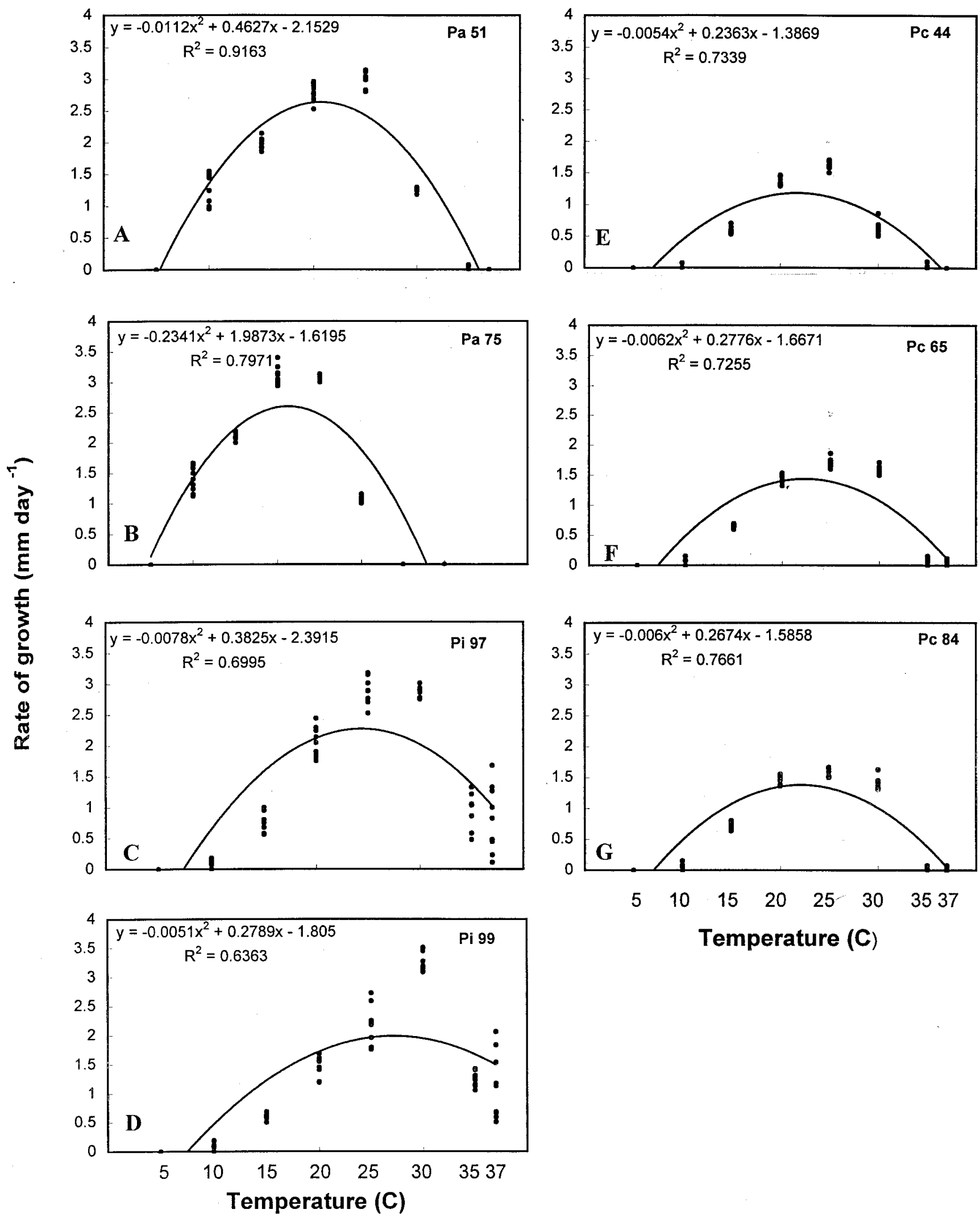

Temperature (C)

Fig. 1. Rates of colony growth at temperatures between 5 and $37^{\circ} \mathbf{C}$. A and $\mathbf{B}$, Isolates of Phaeoacremonium aleophilum (Pa 51, Pa 75). C and D, Isolates of Phaeoacremonium inflatipes (Pi 97, Pi 99). E, F, and G, Isolates of Phaeomoniella chlamydospora (Pc 44, Pc 65, Pc 84). 

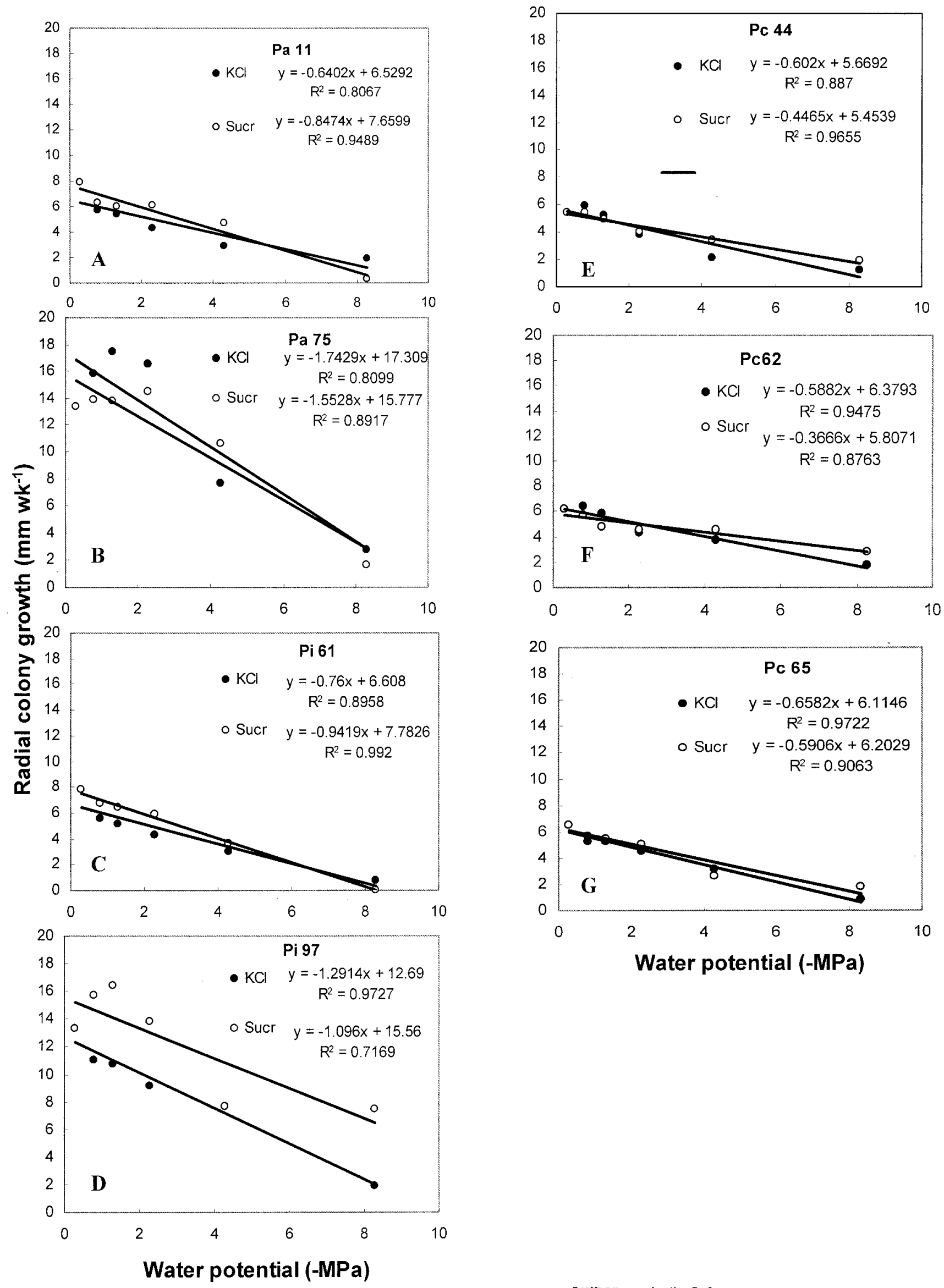

Fig. 2. Mean rate of colony growth of isolates of Phaeomoniella chlamydospora and Phaeoacremonium spp. at $22 \mathrm{C}$ on media amended with $\mathrm{KCl}$ or sucrose to give water potentials of -0.3 to $-8.3 \mathrm{MPa}$. A and $\mathbf{B}$, Isolates of Phaeoacremonium aleophilum (Pa 11, Pa 75). C and $\mathbf{D}$, Isolates of Phaeoacremonium inflatipes (Pi 97, Pi 99). E, F, and G, Isolates of Phaeomoniella chlamydospora (Pc 44, Pc 62, Pc 65). 
treatments and be consistent with isolates of Phaeomoniella chlamydospora and $P$. inflatipes from other areas.

Isolates of $P$. aleophilum from California and South Africa, however, responded very differently to temperature than isolates of $P$. aleophilum from other areas (Italy and former Yugoslavia). Both of these isolates had an optimum temperature for mycelia growth of $25^{\circ} \mathrm{C}$ with little growth at $35^{\circ} \mathrm{C}$. Isolates of $P$. aleophilum from other regions had an optimum temperature for growth of $35^{\circ} \mathrm{C}$. The difference in optimum temperature for growth between Californian and South African isolates and the published temperature optima of other isolates of $P$. aleophilum poses questions about identification of the isolates. $P$. aleophilum is culturally and morphologically similar to $P$. angustius and is difficult to distinguish by morphology alone. Conidia of $P$. angustius are slightly longer and more slender than conidia of $P$. aleophilum. Optimum and maximum temperature for growth, however, are very different and were used to differentiate species because $P$. angustius has a temperature optimum of $25^{\circ} \mathrm{C}$. However, the two species are now considered to be the same (9).

Growth of all isolates was most rapid between -0.3 and $-2.3 \mathrm{MPa}$ water potentials which is in agreement with rates of growth for mesophytic fungi (6). Actual rates of growth varied by species, however, and we expected that isolates within a species would respond to changes in water potential similarly. That is, isolates that are sensitive to changes in water potential would have graphs of regression lines with steeper slopes than isolates that were relatively unresponsive to water potential and the graph of the regression line would have flatter slopes. The three isolates of Phaeomoniella chlamydospora were similarly unresponsive to changes in water potential (Fig. 2E to G), but there was some variation in the response of isolates of both $P$. inflatipes and $P$. aleophilum to changes in water potential. One isolate of both species responded similarly to isolates of Phaeomoniella chlamydospora. Isolates of $P$. inflatipes and $P$. aleophilum that were less responsive to changes in water potential also had growth rates similar to Phaeomo- niella chlamydospora, which may have an influence on their response to water potential. The other isolate of both species was more responsive to decreasing water potential. The isolate of $P$. inflatipes that was sensitive to decreasing water potential grew better on media amended with sucrose than on media amended with $\mathrm{KCl}$.

Variation in response of isolates within two of the Phaeoacremonium species in response to water potential was not expected. Usually, isolates of soil fungi would be expected to respond similarly, but physiological variation of isolates within species is not unusual (12). In their study of Acremonium spp., common endophytes of grass $(28,29)$, Bruehl and Kaiser (3) found effects of water potential varied by isolates within species of Acremonium rather than by species. Isolates within Acremonium species have also varied in response to temperature (30). A review of research on endophytic species by Latch (15) points out that isolates within a species can vary greatly in their metabolism.

Lack of response of suspected endophytic isolates of Phaeomoniella chlamy-
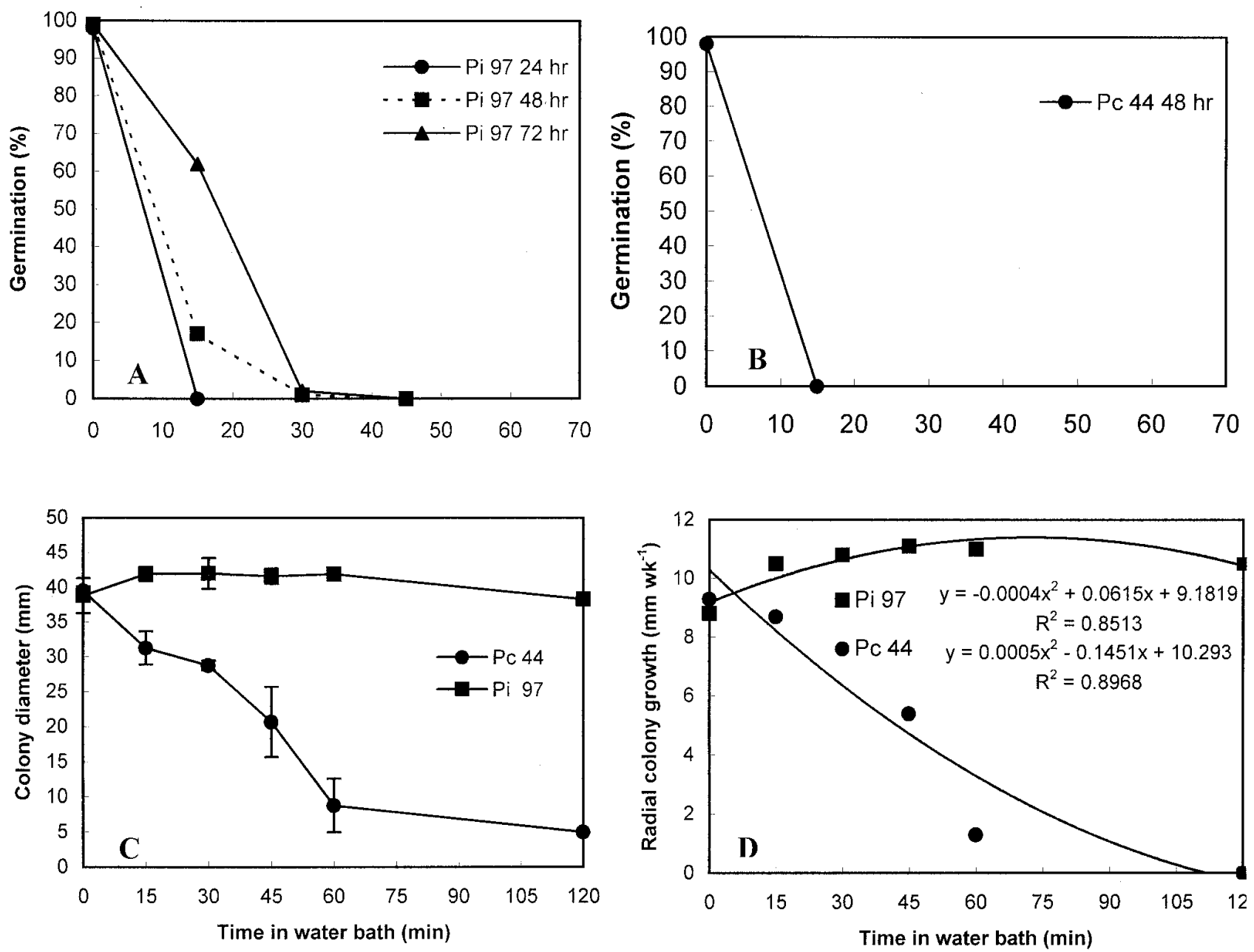

Fig. 3. Conidial germination and growth of Phaeomoniella chlamydospora (isolate Pc 44) and Phaeoacremonium inflatipes (isolate Pi 97). A and B, A conidial suspension of $10^{6} \mathrm{spores} / \mathrm{ml}$ was placed in glass vials and vials were incubated in a hot water bath at $51^{\circ} \mathrm{C}$ for 15 , 30,45 , and 60 min. After each incubation period an aliquot of conidia was plated on PDA amended with $0.1 \mu \mathrm{g} / \mathrm{ml}$ tetracycline (PDA-Tet) and incubated further at $22^{\circ} \mathrm{C}$. $\mathbf{C}$ and $\mathbf{D}$, Plugs of agar with mycelia and spores were incubated in glass vials and placed in a hot water bath at 51 C for 15, 30, 45, 60, and 120 min. After each incubation time plugs were placed on PDA-Tet plates and incubated further at $22^{\circ} \mathrm{C}$. Colony diameter was measured each week for 4 weeks. 
dospora to changing water potential raises interesting hypotheses. Taxonomically, Phaeoacremonium is similar to Acremonium except for the former having pigmented hyphae and spores. Bruehl and Kaiser (3) found that species of Acremonium that are endophytes of grass are unresponsive to changes in water potential in culture. The ability of Acremonium starrii, A. coenophialum, and A. typhium to grow in a wide range of water potentials in grass tissue may be an adaptive mechanism for life as an endophyte. Acremonium spp., which grow in intercellular spaces in host tissue, would be dependent on the moisture and nutritional status of their host.

Adapting to a wide range of water potentials may also be a strategy for Phaeoacremonium spp. and particularly for Phaeomoniella chlamydospora to exist as an endophyte or as a latent pathogen in grapevine xylem tissue. It may be possible for the fungus to continue vegetative development and grow under conditions of low moisture that would stress the host.

Hot-water treatment of grapevine wood for controlling pests and pathogens in propagation material produces mixed results. Nematodes, phylloxera, and phytoplasmas are controlled with the current treatment of $50^{\circ} \mathrm{C}$ for $30 \mathrm{~min}$ (5). Crown gall bacterium, however, which infests much of the propagation material in Australia, is reduced but not eliminated by this treatment (19). This study shows that $51^{\circ} \mathrm{C}$ may not be effective in eliminating or even reducing Phaeomoniella chlamydospora and $P$. inflatipes from dormant cuttings. Heat treatment of fungal mycelium in agar plugs caused a slight reduction in growth rate of Phaeomoniella chlamydospora after $30 \mathrm{~min}$ but did not affect growth of $P$. inflatipes. Methods other than hot-water treatment may be more effective in eliminating Phaeomoniella chlamydospora and Phaeoacremonium spp. from dormant vine cuttings.

\section{ACKNOWLEDGMENT}

This research was supported by the California Grape Rootstock Commission.

\section{LITERATURE CITED}

1. Bertelli E., Mugnai, L., and Surica, G. 1998. Presence of Phaeoacremonium chlamy- dosporum in apparently healthy rooted grapevine cuttings. Phytopathol. Mediterr. 37:7982.

2. Von Broemsen, S., and Marais, P. G. 1978. Eradication of Phytophthora cinnamomi from grapevine by hotwater treatment. Phytophylactica 10:25-27.

3. Bruehl, G. W., and Kaiser, W. J. 1996. Some effects of water potential upon endophytic Acremonium spp. in culture. Mycologia 88:809-815.

4. Burr, T. J., Ophel, K., Katz, B. H., and Kerr, A. 1989. Effect of hot water treatment on systemic Agrobacterium tumefaciens Biovar 3. Amer. J. Enol. Vitic. 39:67-70.

5. Burr, T. J., Reid, C. L., Splittstoesser, D. F., and Yoshimura, M. 1996. Effect of heat treatments on grape bud mortality and survival of Agrobacterium vitis in vitro and in dormant grape cuttings. Am. J. Enol. Vitic. 47:119-123.

6. Cook, R. J., and Papendick, R.J. 1972. Influences of water potential of soils and plants on root disease. Annu. Rev. Phytopathol. 10:349374.

7. Crous, P. W., and Gams, W. 2000. Phaeomoniella chlamydospora gen. et comb. Nov., a causal organism of Petri grapevine decline and esca. Phytopathol. Mediterr. 39:112-118.

8. Crous, P. W., Gams, W., Wingfield, M. J., and van Wyk, P. S. 1996. Phaeoacremonium gen. nov. associated with wilt and decline diseases of woody hosts and human infections. Mycologia 88:786-796.

9. Dupont, J., Laloui, W., Magnin, S., Larignon, P., and Roquebert, M. F. 2000. Phaeoacremonium viticola, a new species associated with Esca disease of grapevine in France. Mycologia 92:499-504.

10. Ferreira, J. H. S., van Wyk, P. S., and Venter, E. 1994. Slow dieback of grapevine: Association of Phialophora parasitica with slow dieback of grapevines. S. Afr. J. Enol. Vitic. 15:9-11.

11. Goheen, A. C., Nyland, G, and Lowe, S. K. 1973. Association of a rickettsialike organism with Pierce's disease of grapevines and alfalfa dwarf and heat therapy of the disease in grapevines. Phytopathology 63:341-345.

12. Griffin, D. M. 1972. Ecology of soil fungi. Syracuse University Press, Syracuse, NY.

13. Harris, R. F. 1981. Effect of water potential on microbial growth and activity. Pages 23-84 in Water potential relations in soil microbiology. J. F. Parr, W. R. Gardner, and L. F. Elliott, eds. Soil Science Soc. Am., Spec. Publ. 9. Soil Science Soc. Am., Madison, WI.

14. Larignon, P., and Dubos, B. 1997. Fungi associated with esca disease in grapevine. Eur. J. Plant Pathol. 103:147-157.

15. Latch, G. C. M. 1993. Physiological interactions of endophytic fungi and their hosts: Bi- otic stress tolerance imparted to grasses by endophytes. Agric. Ecosys. Environ. 44:143156.

16. Lear, B., and Lider, L. A. 1959. Eradication of rootknot nematodes from grape vine rootlings by hotwater. Plant Dis. Rep. 43:314-317.

17. Messenger, A. P. 1948. Grape phylloxera policy. Calif. Dep. Agric. Circular 90.

18. Mugnai, L., Graniti, A., and Surico, G. 1999. Esca (black measles) and brown woodstreaking: Two old and elusive diseases of grapevines. Plant Dis. 83:404-418.

19. Ophel, K., Nicholas, P. R., Magarey, P. A., and Bass, A. W. 1990. Hot water treatment of grape cuttings reduces crown gall incidence in a field nursery. Amer. J. Enol. Vitic. 41:325329.

20. Pascoe, I. 1999. Grapevine Trunk diseasesblack goo decline, esca, Eutypa dieback and others. Aust. Grape Grower Winemaker 429:24-28

21. Robinson, R. A., and R. H. Stokes. 1959. Electrolyte solutions. 2nd Ed. Butterworth Scientific Publications, London.

22. Scheck, H., Vasquez, S., Fogle, D., and Gubler, W. D. 1998. Grape growers report losses to black foot and grapevine decline. Calif. Agric. 52:19-23.

23. Scheck, H., Vasquez, S. J., Fogle, D., and Gubler, W. D. 1998. Three Phaeoacremonium spp. cause young grapevine decline in California. Plant Dis. 82:590.

24. Sidoti, A., Buonocore, E., Serges, T., and Mugnai, L. 2000. Decline of young grapevines associated with Phaeoacremonium chlamydosporum in Sicily (Italy). Phytopathol. Mediterr. 39:87-91.

25. Sommers, L. E., Harris, R. F., Dalton, F. N., and Gardner, W. R. 1970. Water potential relations of three root-infecting Phytophthora species. Phytopathology 60:932-943.

26. Vasquez, S., Gubler, W. D., Luvisi, D. A., and Bianchi, M. L. 1997. Aetiology of grapevine measles in California. Phytopathology 88:S91.

27. Waite, H. 1998. Hot-water treatment of vinifera and rootstock cuttings. Current status and issues. Interim Report. Univ. of Melbourne, Dookie College, Australia.

28. White, J. F., Jr., 1987. The widespread distribution of endophytes in the Poaceae. Plant Dis. 71:340-342.

29. White, J. F., Jr., and Cole, G. T. 1985 Endophyte-host associations in forage grasses. I. Distribution of fungal endophytes in some species of Lolium and Festuca. Mycologia 77:323-327.

30. White, J. F., Jr., and Morgan-Jones, G. 1987. Endophyte-host associations in forage grasses. X. Cultural studies on some species of Acremonium Sect. Albo-lanosa, including a new species $A$. starrii. Mycotaxon 30:8795. 